\title{
A MULTI-SCALAR PHOTOGRAMMETRIC RECORDING APPROACH IN TERMEZ (UZBEKISTAN)
}

\author{
Jorge Angás $^{1 *}$, Paula Uribe ${ }^{2}$, Enrique Ariño ${ }^{2}$, Josep M. Gurt ${ }^{3}$, Verònica Martínez-Ferreras ${ }^{3}$, Shakir Pidaev ${ }^{4}$ \\ ${ }^{1}$ Universidad Politécnica de Madrid, Spain-j.angas@usal.es \\ ${ }^{2}$ Universidad de Salamanca - (uribe, argil)@usal.es \\ ${ }^{3}$ Universidad de Barcelona - (vmartinez, jmgurt)@ub.edu \\ ${ }^{4}$ Institute of Fine Arts, Academy of Sciences of Uzbekistan, Uzbekistan - shakirdjan@mail.ru
}

\section{Commission II, WG II/8}

KEY WORDS: Uzbekistan, Ancient Termez, CORONA Satellite, photogrammetric techniques, 3D reconstruction, open-source libraries

\begin{abstract}
:
This paper presents the preliminary results obtained during the 3D recording campaign carried out in 2018 by the Spanish-Uzbek IPAEB mission in the archaeological site of Termez (southern border of Uzbekistan). Ancient Termez is an important historical city within the Silk Road located in the ancient Bactria region. The archaeological work performed at the site since the beginning of the $20^{\text {th }}$ century allowed a large fortified urban complex to be identified that includes other walled enclosures inside it, i.e., a HellenisticSeleucid fortress founded after the campaigns of Alexander the Great in the late $4^{\text {th }}$ century BC, several Buddhist monastic complexes dated to the Kushan period ( $1^{\text {st }}$ to mid- $3^{\text {rd }}$ centuries), and a large urban settlement dated to the Islamic period which includes the city proper or shahristan and the suburbs or rabad. After the destruction by Genghis Khan in 1220, Termez was rebuilt following a different plan. Major changes involved the movement of the pottery workshops from the rabad to the previous shahristan. The research focuses on: a) the identification, study and archaeological contextualization of ceramic production centres located in different areas of the ancient Termez from the Kushan to the Islamic period (1st to 14th centuries AD); b) the integration of the pottery workshops into the general topography of the site and c) the study of their evolution in relation to the transformation of the urban design. Since the site is currently located in a military area - close to the border area between Uzbekistan and Afghanistan -, the archaeological work is restricted to specific zones and the use of aerial devices such as drones is forbidden. However, this research requires both micro and macro spatial approaches to accurately record all the archaeological structures and to evaluate the integration and evolution of the pottery workshops into the general topography of the city. In order to fill this gap, declassified images of the CORONA satellite program were analyzed and compared to historical and archaeological data. In addition, we propose a geometrical and graphical recording and distribution system of the kilns -located in the rabad and the shahristan-and the ceramics produced and used in Termez during the period studied by means of photogrammetric techniques. The results are aimed at management through open-source 3D formats and web mapping GIS libraries combined with historical satellite information that defines the different archaeological areas.
\end{abstract}

\section{INTRODUCTION OF THE ARCHAEOLOGICAL SITE: TERMEZ (UZBEKISTAN)}

Termez is located on the right bank of the Amu Darya and near the mouth of its tributary, the Surkhan Darya. The region of Termez is characterized by an almost flat topography (mean altitude $300 \mathrm{~m}$ ) and a few small hills that are the southernmost residual reliefs of the Baysuntau-Kugitangtau range. The Amu Darya-Surkhan Darya floodplain forms part of the Afghan-Tajik depression which comprises a Hercynian basement formed by highly metamorphosed Precambrian-Palaeozoic rocks and by Permian-Triassic sedimentary and volcanic rocks. The city was one of the most important urban centres in northern Bactria/Tokharistan, a historical region that included the present-day territories of southern Uzbekistan and Tajikistan (Figure 1), and northern Afghanistan. The exact date of the founding of Termez is unknown. It has been related to the campaign to conquer the ancient Bactria and Sogdiana by Alexander the Great (between 329 and 327 BC) as well as dated in the period of the first Seleucid kings (Leriche 2001; Pidaev 2001; Leriche/Pidaev 2007; Leriche/Pidaev 2008).
Termez includes several walled enclosures inside it. The earliest of them has provided evidence of Greek occupation. Thus, pottery in Hellenistic tradition has been recovered in the lower levels of the fortress (Citadel) located on the right bank of the Amu Darya. According to their features, the vessels should be dated to the late 4th or the early 3rd centuries AD (Pidaev, 1991). The second enclosure (Tchingiz Tepe) is located NorthWest of the Citadel. A recent archaeological investigation carried out in several sectors by our team, comprising a complete study of the archaeological sequence supported by radiocarbon analysis, allowed to date the construction of the walls between the early $2 \mathrm{nd}$ and the mid-1st centuries BC. Therefore, the walls of Tchingiz Tepe could be dated immediately after the arrival to the region of the nomadic tribes known by the name of Yuezhi (Martínez et al. 2014; Gurt et al. 2015). Under the rule of Kushan kingdom (1st century AD mid-3rd century AD) a new fortified area, the sharistan, was built. During this period, Termez became an important religious centre that hosted a number of Buddhist monasteries such as Fayaz Tepe, Kara Tepe, Tchingiz Tepe and Zurmala (Abdullaev, 2013; Stavisky, 2001).

\footnotetext{
* Corresponding author
} 
In the mid-3rd century $\mathrm{AD}$, the Kushan kingdom became a vassal state of the Sasanian Empire; the Buddhist monastic complexes were reformed, changing their original functionality. In the 5th century $\mathrm{AD}$ a succession of nomadic peoples established themselves as autonomous entities in the region and the Buddhist monasteries were finally abandoned. The city reached its greatest extension in the Islamic period. After the destruction of the city carried out by Genghis Khan in 1220 , the city witnessed a period of urbanistic changes which involved the movement of the pottery workshops from the rabad to the previous urban area or shahristan. Little is known about Termez after this period, which ended in complete depopulation around the 17th or 18th centuries (Karimov 2001; Leriche 2001, 81; Barthold 2002, 58).

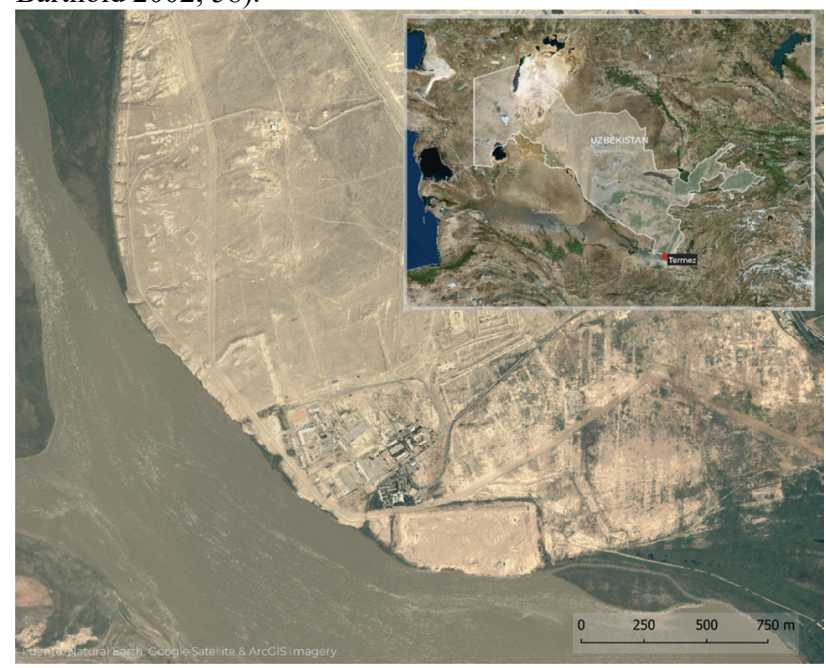

兔 :arax xpe

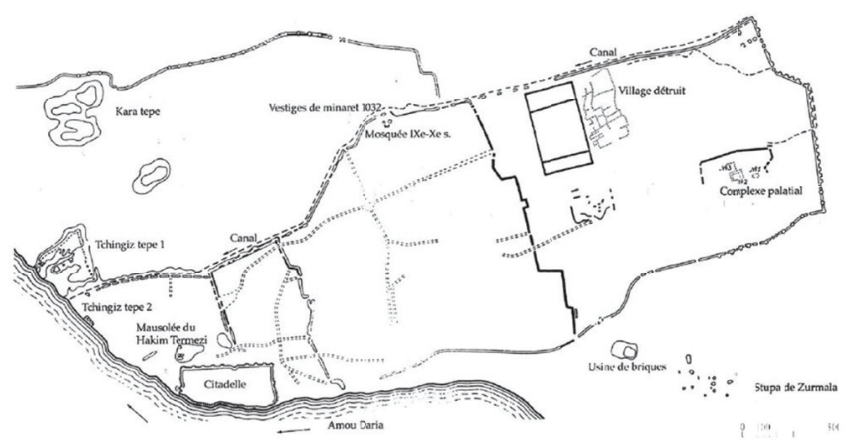

Figure 1. Location of the archaeological site of ancient Termez close to the border area between Uzbekistan and Afghanistan (Natural Earth, Google Satellite view and ArcGIS Imagery) (above). Map of the ancient settlement of Termez (below) (Pidaev, 2001b).

\section{RESEARCH OBJECTIVES: A MULTI-SCALAR APPROACH}

The Spanish-Uzbek IPAEB mission has been working in Termez since 2006, and a process of 3D geometric documentation with different scopes was initiated in the latest campaign (2018).

One of the reasons for this is related to the conservation of the archaeological structures of Termez. Many of them are built of mud and it is difficult to preserve them once excavated (O'Grady et al., 2018). This phenomenon gives special relevance to graphic and geometry recording techniques, not only as a scientific guarantee, but also as an indispensable tool with a view to any kind of restoration or consolidation work in the future.

The data recorded in Termez will be used in a multi-scale record of archaeological artefacts related to ceramic production (Figure 2), ranging from tiny ceramic shards to whole archaeological landscapes, although the concept of multi-scale data management and visualization is playing an increasingly more important role in the context of Cultural Heritage (Boutsi et al., 2019) combining dissemination and scientific purposes. In this regard, all the documentation acquired has had the following aspects as a main objective:

- The reconstruction of the archaeological landscape previous to the Soviet-Afghan War.

- The geometric documentation of each different work level in the interests of its conservation.

- The integration of all the data on a $2 \mathrm{D} / 3 \mathrm{D}$ web mapping platform.

-To present different hypotheses in relation to the topography of the archaeological sites and the potential identification of buried archaeological structures.

The first level deals with the topography and satellite images of the archaeological site with the construction of a Digital Elevation Model (DEM). The aim of the first level was to obtain a DEM previous to the Soviet-Afghan War. This information allows a comparison to the current DEM in order to ascertain changes in the archaeological remains. Furthermore, this data set allows us to compare, interpret and georeference different archaeological structures that are not visible on the surface today.

The second level deals with the recording of excavated areas with special attention to ceramic kilns. In this regard, we documented five ceramic kilns distributed across three different areas of the site. The final objective of this documentation is to obtain a volumetric and spatial distribution to be able to perform a digital reconstruction and a typollogy of the kilns. It is difficult to preserve them once they have been excavated; in view of this, the degradation suffered by these materials needs to be documented on a yearly basis.

The third and last level aims to develop a typology of ceramic forms. The photogrammetry of these movable objects will allow us to reconstruct profiles, describe and quantify the formal changes, and observe their degree of standardization according to their volumetric evolution. In addition to the three documentation levels mentioned above, we took the opportunity to $3 \mathrm{D}$ record by photogrammetric techniques some bone remains as well at the archaeological sites where the kilns were found.

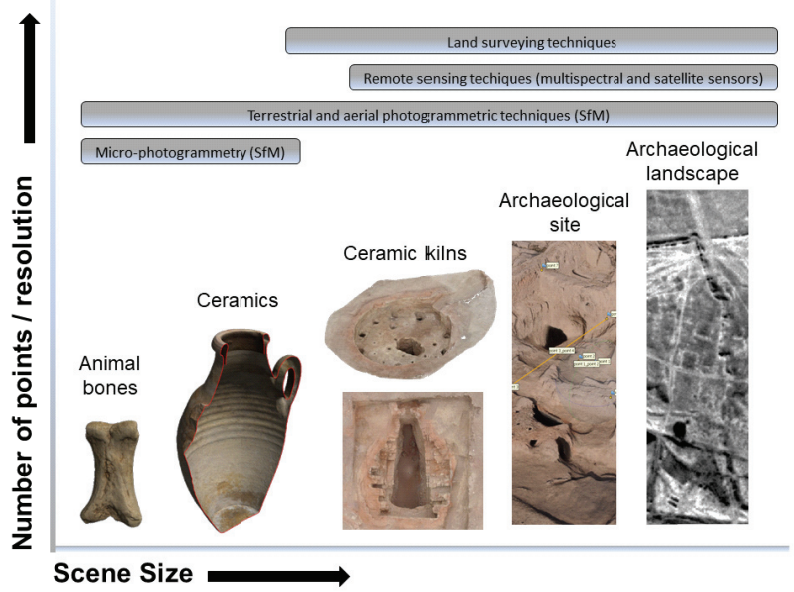


Figure 2. Multi-scale classification of the geometric record by resolution and size according to Cultural Heritage typology carried out with different techniques.

\section{METHODOLOGY}

\subsection{Archaeological landscape. Use of satellite image}

Due to the impossibility of using drones, the satellite images of the CORONA program were investigated. The declassification process in 1995 of more than 800,000 images taken under the CORONA satellite reconnaissance program by the United States between the 1960s and 1970s during the Cold War. They provide great potential material for territorial analysis and interesting element detection thanks to the spatial resolution obtained from the continuous satellite performance improvement. However, the declassification process did not include additional information related to the cameras used nor to the satellite position at the instant of image capture time. Moreover, camera calibration reports have not been declassified by the National Geospatial-Intelligence Agency (NGA) (information provided by the USGS EROS User Services in September 2018). Because of that, using these images in a photogrammetric or a visual analysis based on its digital processing context is very difficult. Nevertheless, CORONA imagery is one of the best alternatives when there is a lack of images and cartographic resources in specific places due to different reasons. This is especially important in those places where morphological changes have taken place since the capture of this information due to the Soviet-Afghan War or other natural or anthropic effects. This factor could significantly change the interpretation of the archaeological landscape.

The acquisition of these images by the USGS has allowed for fitting them through common GCP support points between both dates taken by a GNSS sensor. The control points are basically reduced to some architectural structures and irrigation canals.

These structures have remained intact for at least 60 years and are easily identifiable in both historical periods -before and after the War- .

The advantage of using these images was the possibility of reconstructing the DEM before the war, which is likely to have changed the morphology of the archaeological site.

These images have been the basis for geometric and visual comparison to current satellite images. The detection and evaluation of these differences is useful to verify visual anomalies on the ground.

\subsubsection{Data acquisition}

First, the DEM reconstruction of the 1960s site was carried out using two stereoscopic images acquired from the USGS (Figure 3), taken during mission 1012-1 of the American CORONA reconnaissance program, October 17-20, 1964 (the selected images were taken on October 20,1964) with a J-1 camera on board the KH-4A satellite. The stereoscopic nature of the images allows for creating digital terrain models using photogrammetry software with a series of limitations which will be described later on. The surface covered by the two stereoscopic images is approximately $300 \mathrm{~km}$ long by $20 \mathrm{~km}$ wide, the area of study being located in the central area (Figure 3 ), which means that image distortion on the area of study will be minimal (Watanabe et al., 2017). The $J-1$ was a panoramic camera with two lenses $609,602 \mathrm{~mm}$ in focal width which took stereoscopic images $30^{\circ}$ forward, stereoscopic images $30^{\circ}$ backwards, and a $70^{\circ}$ total scanning angle perpendicular to the satellite. The images had a $17 \times 232 \mathrm{~km}$ nominal coverage.
In addition to the $J-1$ camera, the satellite had a series of auxiliary cameras that took images of the total space captured by the individual lenses, of the horizon, and of the sky. The latter provided external orientation in the photogrammetric restitution of the images (Galiatsatos, 2004; Goosens et al., 2006).

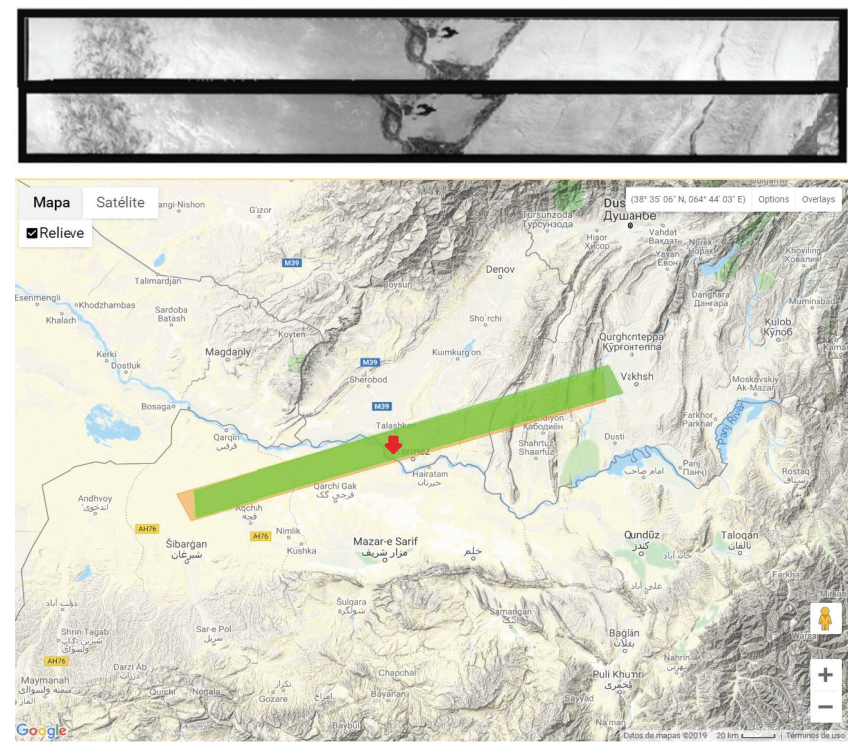

Figure 3. Stereoscopic images used: DS1012-1039DA163 and DS1012-1039DF157 (above) and their footprints (green and orange) on the ground (below) (USGS-EarthExplorer).

Second, the rest of the images on Table 1 were used in the photo-interpretation process. Among all of them, image DZB00403800056H011001 provided us with the best spatial resolution in order to identify archaeological remains. This image was taken during missiion 4038 of the American CORONA reconnaissance program, which was operational from July 1963 to June 1967. The Keyhole (KH) KH-7 images are 9 inches wide, vary in length from 4 inches to 500 feet long, and have a resolution of 0,60 to $1,21 \mathrm{~m}$. (2 to 4 feet).

Third, all the images and data were integrated under the same global coordinate system, in thisi case EPSG 3857 (WGS 84 web Mercator) with coordinates expressed in meters and used on web applications, which would allow us to use these materials and results in a web mapping environment.

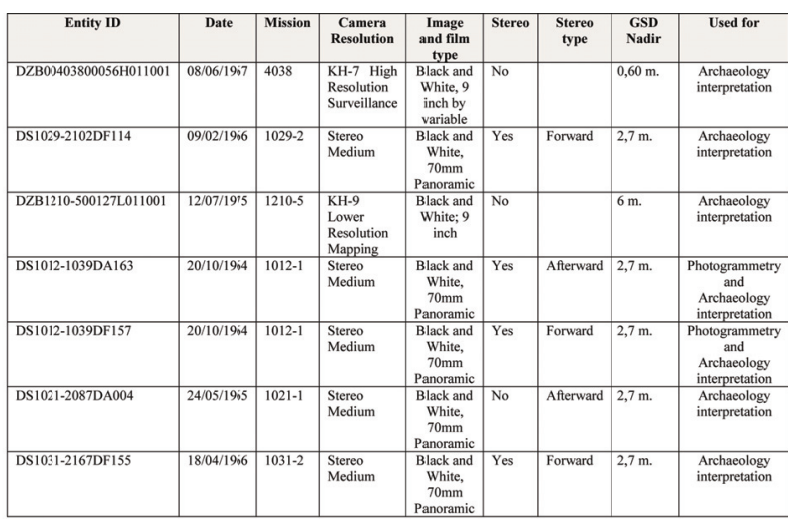

Table 1. Classification of the CORONA images declassified that have been used for this study. 


\subsubsection{Image processing}

The photogrammetric process includes a total of 52 control points in order to achieve better adjustment in the spatial referencing of the block of images during the photogrammetric restitution process. These points were taken in the field in April, 2018 using a GNSS sensor with sub-metric accuracy. Their distribution is related to the localization of a series of interesting archaeological elements which were worth documenting during this fieldwork campaign. These GCP occupied a small space within the whole image. Therefore, we used QGIS-digitizing tools to digitize a series of points on the georeferenced CORONA images. Although the accuracy of the resulting coordinates may be questionable, they were very easily localized on the images during the photogrammetric process. This process is justified in view of the lack of a wide orthophotography of the area and of the impossibility of creating it ourselves as drones are not allowed in this zone.

We mainly used two software products for photogrammetric restitution. One is ERDAS Imagine Photogrammetry; in the non-metric cameras category we worked with focus width $(609,602 \mathrm{~mm})$ and the resolution used in scanning $(7 \mu \mathrm{m})$ to set the interior orientation. This model is fit to use with the CORONA images free from interior calibration parameters of the main and fiducial points (Altmaier and Kani, 2002; Galiatsatos, 2004). We also used The Automatic Terrain Extraction tool (ATE), which allows for obtaining DEM from the restituted photogrammetric block (Bellido, 2018).

Next, we performed a photogrammetric restitution based on the SfM technique in Agisoft Metashape Professional (Watanabe et al., 2017). Like Imagine Photogrammetry, interior orientation was obtained based on focus width and scanning resolution. Fiducial points cannot be localized given that they are inexistent, thus distortion rates are left blank so that the software can calculate them during bundle block adjustment.

Following the bibliography on CORONA image correction (Shin and Schenk, 2008) and on rotation angle measurement based on GPS data (Wierzbicki and Krasuski, 2015), we carried out a first estimation of the exterior orientation parameters (Table 2):

\begin{tabular}{|l|l|l|}
\hline Image & DS1012-1039DA163 & DS1012-1039DF157 \\
\hline $\mathrm{X}_{\mathrm{o}}$ & $7.477 .170 \mathrm{~m}$ & $7.489 .300 \mathrm{~m}$ \\
\hline $\mathrm{Y}_{\mathrm{o}}$ & $4.485 .140 \mathrm{~m}$ & $4.490 .290 \mathrm{~m}$ \\
\hline $\mathrm{Z}_{\mathrm{o}}$ & $185.000 \mathrm{~m}$ & $185.000 \mathrm{~m}$ \\
\hline Yaw & $244^{\circ}$ & $244^{\circ}$ \\
\hline Pitch & $-16,375^{\circ}$ & $-16,375^{\circ}$ \\
\hline Roll & $0^{\circ}$ & $0^{\circ}$ \\
\hline
\end{tabular}

Table 2. Table of the initial exterior orientation parameters of the images.

Both photogrammetric restitution processes are aimed at obtaining an orthorectified and georeferenced image. In this regard, numerous approximations have been performed by changing the images used in multiple combinations: whole images, images cut over the area of study, non-georeferenced images, images georeferenced with $2^{\text {nd }}$ degree polynomials and images georeferenced with $1^{\text {st }}$ degree polynomials (affine transformation). Furthermore, both GPS and QGIS-digitized control points have been interchangeably used to obtain the desired result.

Unfortunately, we were not able to perform the DEM with the selected CORONA images due to overlapping problems between them and a lack of key data, unclassified by the NGA for photogrammetric restitution. Consequently, in order to reconstruct the DEM of recent times, we obtained altimetry data from the relief map by Dumont, Reynard and Person in the context of the French-Uzbek archaeological mission in Bactria
(Pidaev, 2001a). Figure 4 shows the altitudinal data in level curves at 0,5 meter intervals and in a series of bench marks and topographic points. The localized walls and buildings of the site appear as auxiliary information providing context to the relief.

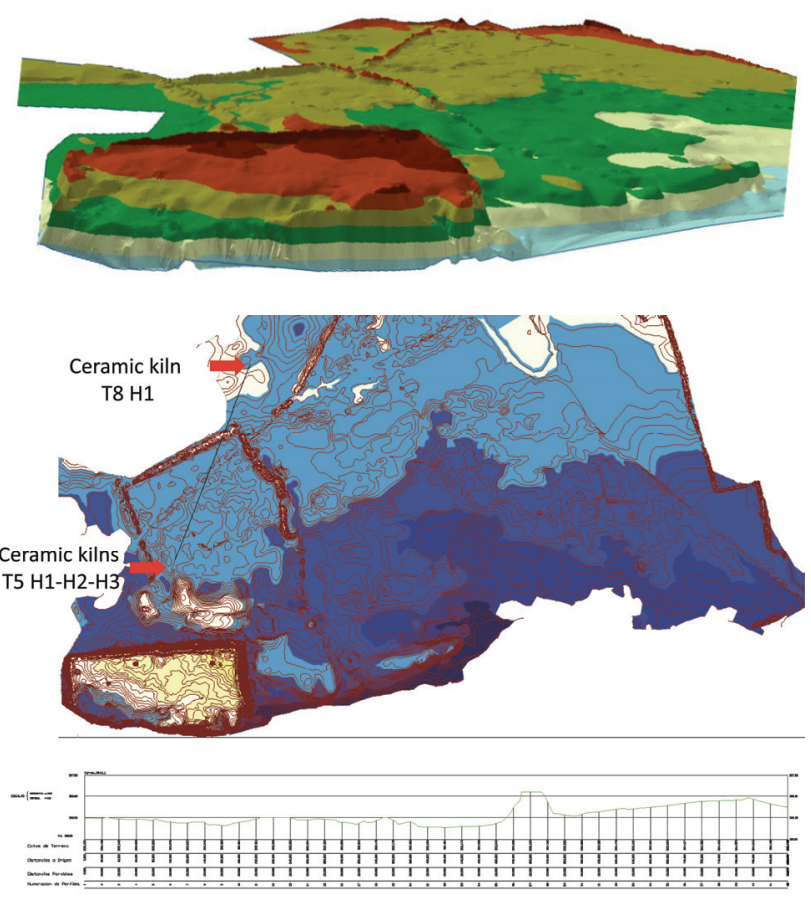

Figure 4. Interpolated 3D model of current period with the location of the ceramic kilns (above). Longitudinal section on the DEM between the T5 and T8 area of ceramic kilns (below).

As to archaeological interpretation, the image has been adjusted in different ways in order to improve the visualization of remains still buried. First, we performed basic contrast, brightness and histogram adjustments. Next, the work method's algorithms were applied to the LiDAR data, namely Analytical Hillshading, Hillshading from multiple directions, Simple Local Relieve Model, Principal Components Analysis, Sky-view Factor and Positive/negative openness.

\subsection{Ceramic kilns and archaeological excavations. Terrestrial photogrammetry}

\subsubsection{Data acquisition}

The second documentation level involved acting over different ceramic kilns in the site. Due to logistic difficulties in the field, we used those photogrammetric techniques that would allow for rapid extensive documentation.

Regarding the photogrammetric system used for the data extraction of the kilns already excavated, a 5 meter pole with a micro four thirds Olympus EPM 1 camera and a Zuiko Digital ED lens $12 \mathrm{~mm} \mathrm{f} 2$ perpendicular to the ground was set up. The final height obtained with this system was 5,7 meters with an angle between $40^{\circ}$ and $45^{\circ}$ in order to facilitate data collection with a linear movement every two meters, both longitudinally and transversal to the excavation so as to obtain a redundant overlap between images that was valid for three-dimensional reconstruction. 

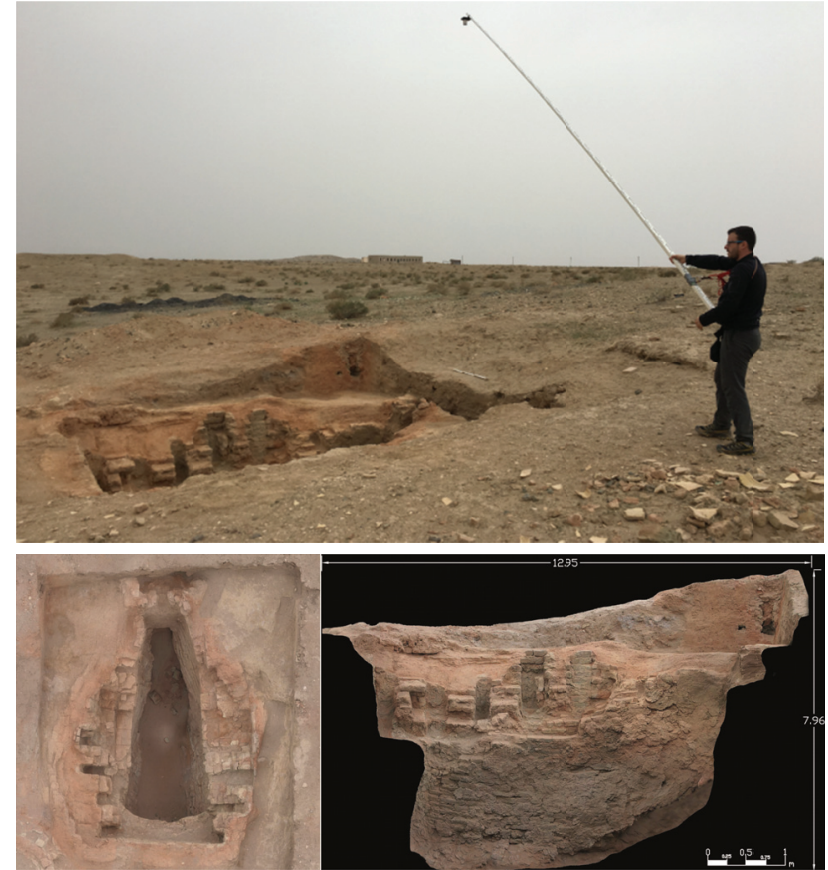

Figure 5. Data acquisition using photogrammetric techniques in the ceramic kiln T2 H2 and results (orthophoto and section).

Taking into account the height of the camera and the dimensions of the sensor used (micro four thirds $17.3 \times 13 \mathrm{~mm}$ ), the resolution of the camera (12 Mpx.) and the focal length (12 $\mathrm{mm}$ ), we obtained an 8,2 meters $\times 6,2$ meters image footprint with a resolution of 2 millimetres per pixel, with an overlap between longitudinal and transverse images of $65 \%-70 \%$ (Figure 5). This technique was used at several points of the archaeological site as it allows digitizing an area of approximately 2000 square meters in just one hour in high resolution, which guaranteed documentation in a short time with a better resolution obtained in the final orthophoto set. The work carried out in $\mathrm{T} 8 \mathrm{H} 1$ allowed us to find a kiln prior to the excavation of this area, based on the change of colour of the ground due to the humidity of the mud/sun-dried brick walls, as well as the large ash stains. The metric references were taken with a laser distance measuring device.

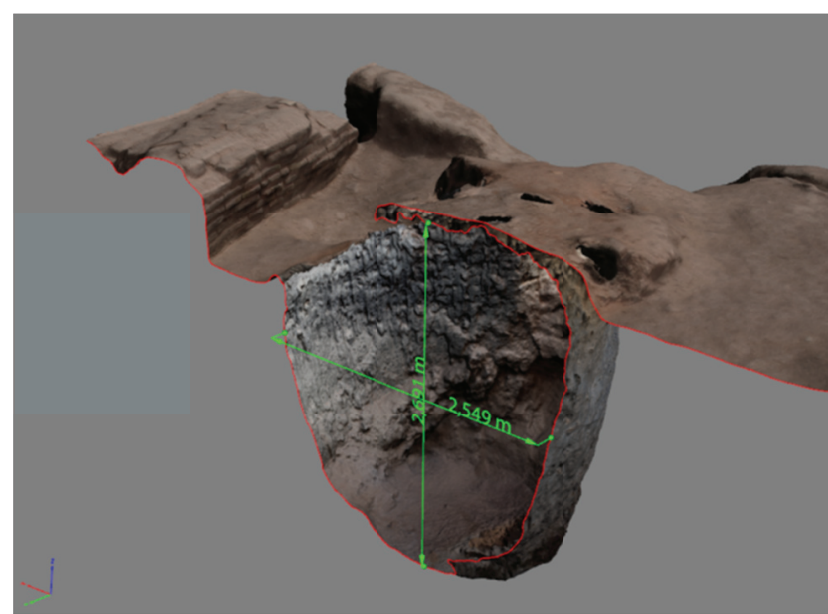

Figure 6. Isometric view on the 3D section generated in format PDF 3D of the ceramic kiln T5 H1.

\subsubsection{Image processing}

The documentation collected was processed using Agisoft Methashape Professional. The results were exported in different formats with a view to facilitating a typological study that would be easy to manage by the whole technical team. Thus, we created a web platform that could be accessed online with a browser in high resolution and different types of scale:

- 3D point clouds on Potree (free open-source WebGL based point cloud rendlerer for large point clouds). Potree based upon three.js library (Schuetz, 2016).

- JSON meshes for the browser viewer and 3D PDF for information sharing (Figure 6).

- Web mapping of each orthophoto of the excavation sites using Leaflet and open-source JavaScript library (Figure 11).

\subsection{Ceramics. Close Range Photogrammetry}

\subsubsection{Data acquisition}

For the final documentation level we used close range photogrammetry techniques on the main ceramic vessels in the Termez laboratory close to the site. We designed a portable homogeneous light system, a rotating plate, with a Canon 6D full frame camera with a fixed $50 \mathrm{~mm}$ lens and a Colour Checker calibrated colour chart (Figure 7). The automation of this geometric reconstruction process with low cost techniques is aimed at generating a three-dimensional repository of the main pieces recovered that allows for reproducing any geometric and graphic millimetre details. This factor will allow us to extract and to chronologically divide the standardization of the ceramic forms and their dimensions in each historical period.

In spite of the long hours that post-processing each of the ceramic remains takes (rotations, masks, alignment, scaling, etc), this technique allows for crucial quick data collection in locations with complicated logistics.

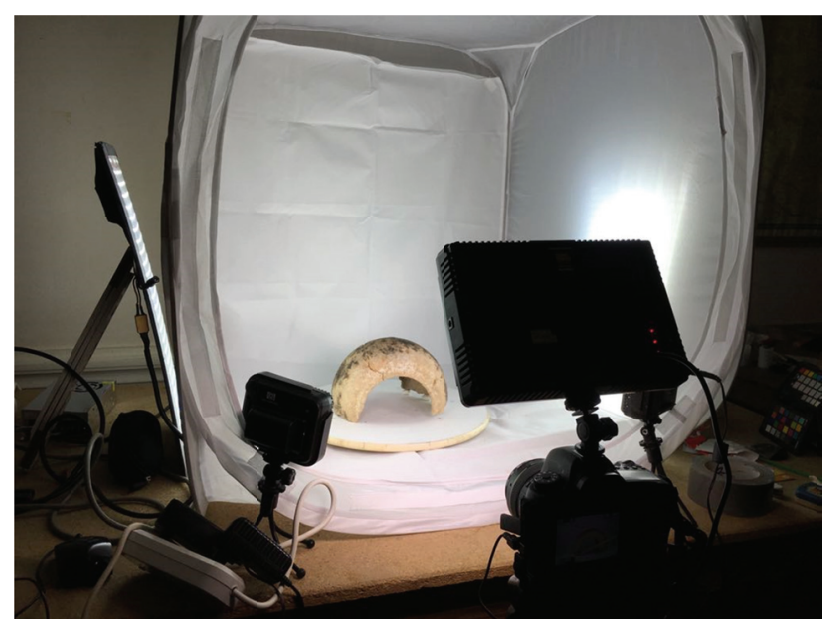

Figure 7. Data acquisition ceramic process by means of a portable close range photogrammetric techniques.

\subsubsection{Image processing}

This data was also post-processed with Agisoft Methashape Professional. In this case, each piece was processed in a certain specific way given that we applied a minimum of four complete 
turns per piece at different heights with the same homogeneous lighting, taking each photo every six degrees. Once the model was scaled, the results were converted to point clouds with the Potree converter so as to finally use this platform as a viewer. Furthermore, the final meshes were exported to JSON models for use on a web browser with HP3D_0.0.4.min.js, jquery1.9.1.js, Handpas_1.0.1.min.js, and three.js libraries.
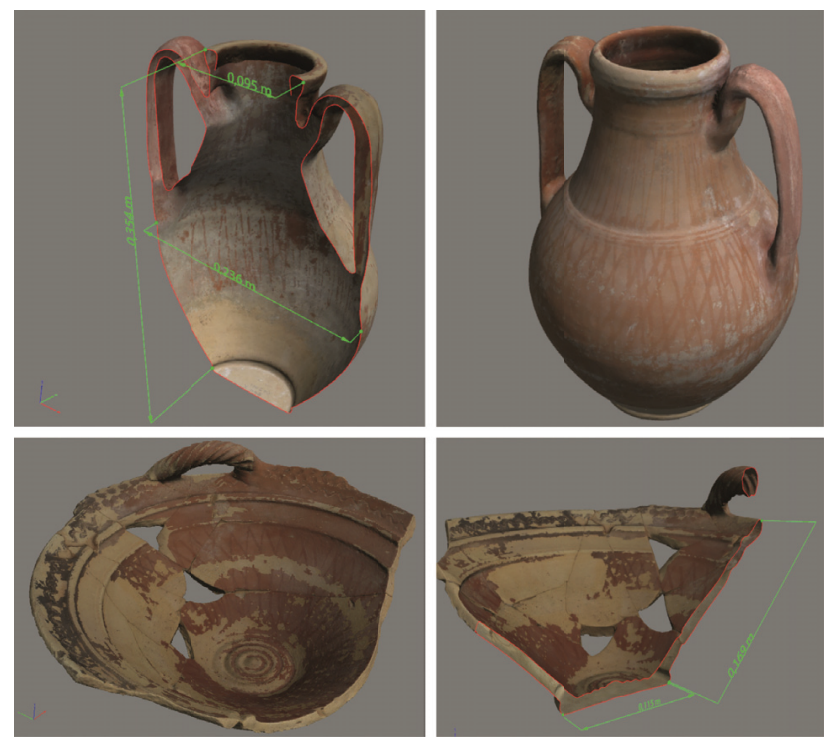

Figure $8.3 \mathrm{D}$ reconstruction of the different ceramic objects recorded in Termez and their geometric use by means of 3D PDF and JSON formats.

\section{RESULTS}

First, the results obtained were analyzed separately with the objective of subsequently generating an integrated web mapping system that combines:

a) Three-dimensional models (point clouds, meshes).

The ceramics, kilns and archaeological excavations documented were converted to point clouds through the free open source WebGL Potree. Parallel 3D PDF files were generated (Figure $8)$.

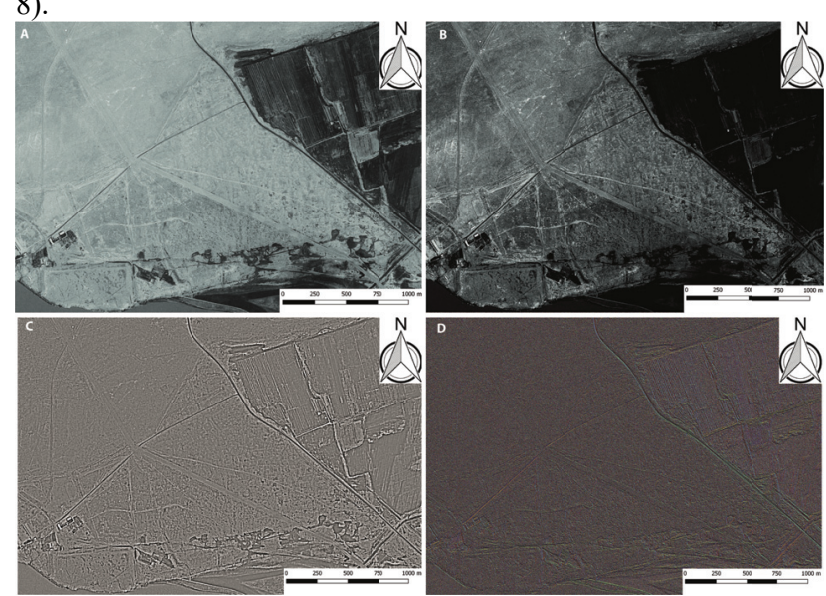

Figure 9. Different visualizations: a) CORONA Image DZB00403800056H011001; b) The same image with increased contrast; c) Simple Local Relieve Model (Radius for trend assessment [pixels]: 20 , histogram equal with $2 \%$ cut-off for 8 bit); d) Principal component analysis of Hillshading (Band 1 of

16 directions of Hillshading and sun elevation angle $35^{\circ}$ ).

b) Orthophotos of the kilns, excavated areas and historical satellite images. Orthophotos were implemented in web mapping using the open source Leaflet library. The objective is to geospatially relate different layers of CORONA information and current orthophotos.

The reconstruction of the site could not be completed due to the failure to obtain an old DEM from the CORONA images at our disposal. However, we were able to reconstruct the current site thanks to the DEM (Figure 4) gemerated from the interpolation of points with altitudinal data extracted from the level curves in the previously cited relief map of the site in the ancient Termez. As to the archaeological interpretation, the photointerpretation (Figure 9, 10,11) has been carried out based mainly on the CORONA image with the highest resolution, which has also been georeferenced and tiledl for the Leaflet library (DZB00403800056H011001). In terms of the visual improvement in order to identify the archaeological remains, the best results were obtained with the Simple Local Relieve Model. This algorithm is based on eliminating the most notable morphological elements to reveal the smallest scale record (Kokalj and Hesse, 2017).
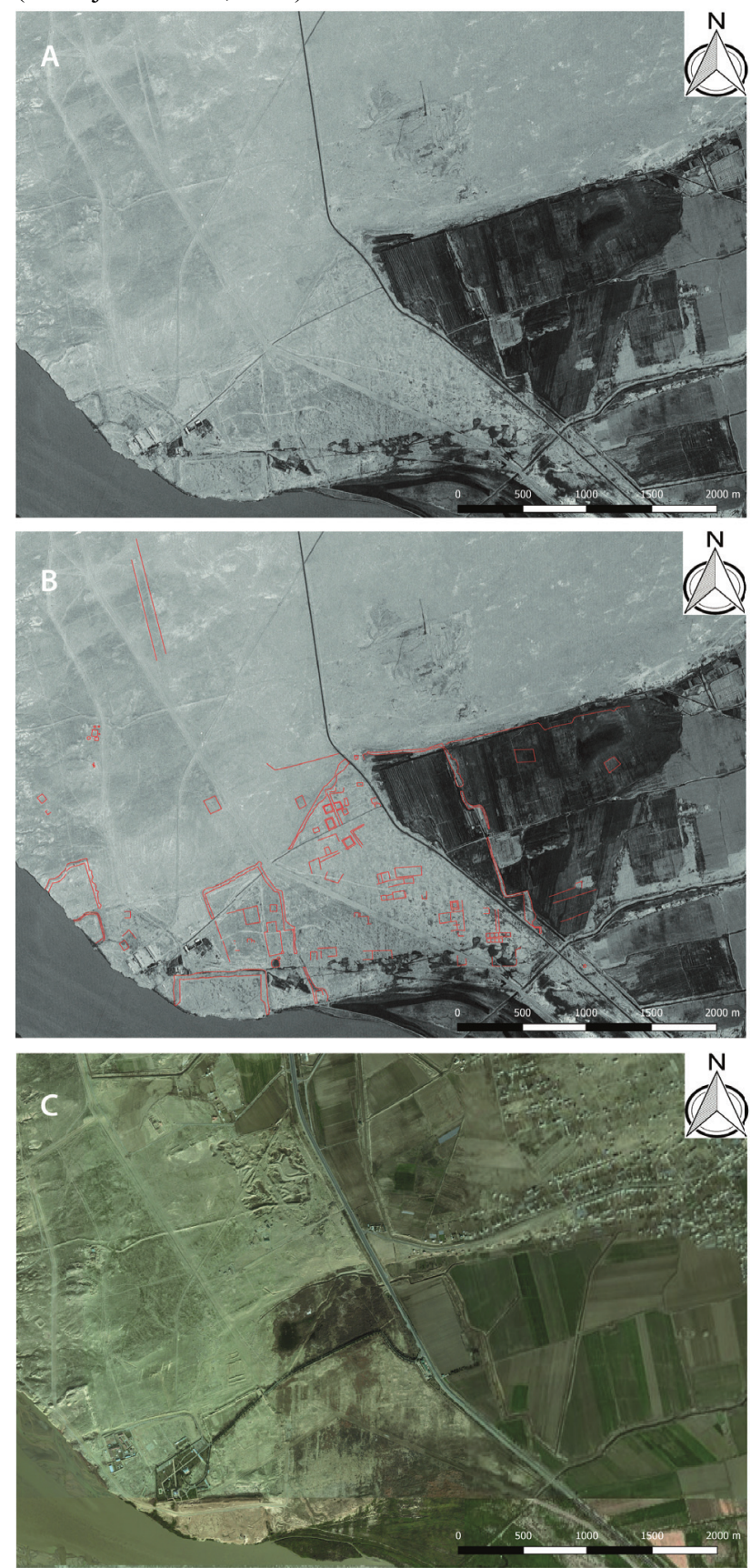
Figure 10. The archaeological interpretation through the CORONA Image DZB00403800056H011001.

a) CORONA image DZB00403800056H011001. b) Archaeological interpretation from DZB00403800056H011001 image. c) Google Satellite view.

\section{CONCLUSION AND FUTURE DEVELOPMENTS}

The study demonstrates that the use of CORONA images represents a key source of information in archaeology since in many cases it is virtually the only one for the reconstruction of the pre-war archaeological landscape. The use of drones would have provided useful updated information on the current state of the site, but would not have allowed the reconstruction of the archaeological landscape 50 years ago. The end of the 1960s and the beginning of the 1970 s period precedes agricultural mechanization and urban development and thus many of the sites studied at that time were well preserved. Above all, it allows for comparing ground anomalies to corroborate buried archaeological structures. However, the spatial resolution and spectral amplitude does not allow a detailed study of archaeological structures of small dimensions.

Its use allows us to obtain a joint reading of the reconstruction of the archaeological landscape if we combine this type of information with web mapping systems that integrate different types of $2 \mathrm{D}$ or $3 \mathrm{D}$ information. 2D data was organized by tiling the different satellite images and interpreting them in different layers which allows for overlapping two images, drawing and converting to GeoJSON (Figure 11) using the Leaflet JavaScript library. As to $3 \mathrm{D}$ models, we used Potree point clouds and JSON meshes mostly in the three.js library.

In spite of the great potential of the CORONA images, the difficulties involved in correcting their geometry to obtain adjusted spatial information means that it has not been possible to complete the DEM reconstruction of ancient Termez. This difficulty derives from a lack of auxiliary information which was excluded from the declassification process of 1995. The methodology applied here includes a series of auxiliary requirements in order to address this shortcoming in this case study.

Even when it is not possible to carry out the photogrammetric restitution process, the digital processing and image georeferencing is an alternative when it comes to finding elements of interest or using the images as reference points in the visual diachronic analysis of the territory. This processing requires polynomial geometric correction which is hindered by a lack of cartographic reference resources in certain places and by the time difference between the localization and the checking of control points.

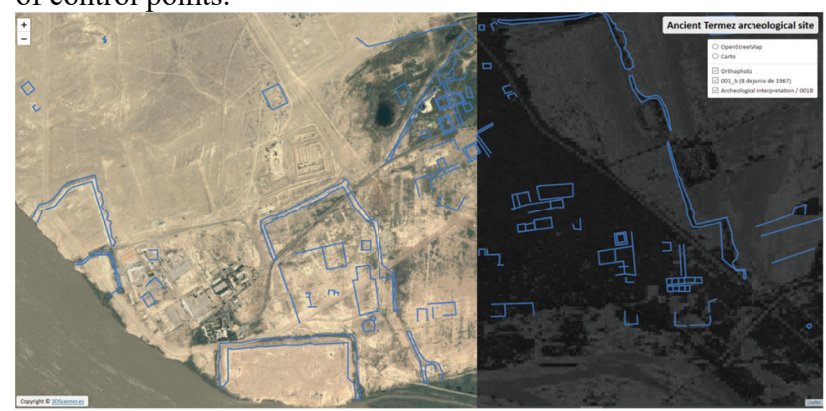

Figure 11. Final web mapping that includes: Google satellite view, diachronic images of CORONA, archaeological interpretation and georeferenced links to different 3D models typology (ceramics and kilns).
As to the NGA failing to include auxiliary data in the declassification process of the CORONA images, this is an issue that should be debated as this information would clearly help the scientific community in the use of these images. First, knowledge on this images and their use would grow exponentially especially in the field of remote sensing, where the processes associated with photogrammetry are not very advanced in spite of being closely related. However, the auxiliary information used throughout the CORONA program to identify interesting elements is not likely to be compatible with the new technological tools for a camera's interior orientation and the exterior orientation of images in space.

In the next few years we will continue to carry out new campaigns with the purpose of verifying the data obtained from the CORONA satellite in the field, and we will also use the low altitude photogrammetric techniques described with other types of multispectral sensors.

Finally, the conclusion in terms of using JavaScript libraries on collaborative development platforms (GitHub) together with HTML5 Canvas is that this allows for a vast set of possibilities which favour the use of these models with contextual information associated with a database. They constitute an exceptional multi-scale documentation tool which meets many of the requirements we consider essential for our research: high online and offline measurement and graphic capability, morphologic information extraction, use of filters and texture, easy to use with a browser supporting WebGL with no additional software, and above all, it is an open system that can be programmed into any implementation we might need to develop in the future.

\section{ACKNOWLEDGEMENTS}

This work was supported by two R\&D\&I projects, CERAC (HAR2016-75133-C3-1-P) led by V. Martínez and J.M. Gurt, and CONCERAC (HAR2016-75133-C3-3-P) led by E. Ariño, all funded by the Spanish Ministry of Science, Innovation and Universities. Foundation Palarq supported the archaeological campaign in Termez in the year 2018. V. Martínez worked on this paper through the post-doctoral research contract Ramón y Cajal (RYC-2014-15789).

\section{REFERENCES}

Abdullaev, K., 2013. The Buddhist culture of Ancient Termez in old recent finds. Parthica, 15, pp. 157-187.

Altmaier, A., and Kany, C., 2002. Digital surface model generation from CORONA satellite images. ISPRS Journal of Photogrammetry and Remote Sensing, 564, pp. 221-235. https://doi.org/10.1016/S0924-27160200046-1

Bellido, A., 2018. Análisis del potencial de las imágenes del programa Corona a través de la reconstrucción del paisaje arqueológico del yacimiento de Termez (Uzbekistán). Trabajo Fin de Máster. Universidad de Zaragoza.

Boutsi, A.-M., Ioannidis, C., and Soile, S., 2019. Interactive online visualization of complex 3D geometries, Int. Arch. Photogramm. Remote Sens. Spatial Inf. Sci., XLII-2/W9, pp. 173-180. https://doi.org/10.5194/isprs-archives-XLII-2-W9173-2019

Galiatsatos, N., Donoghue, D. N. M., and Philip, G., 2008. High Resolution Elevation Data Derived from Stereoscopic CORONA Imagery with Minimal Ground Control: An 
Approach Using Ikonos and SRTM Data. Photogrammetric engineering, 14.

Galiatsatos, N., 2004. Assessment of the CORONA series of satellite imagery for landscape archaeology: a case study from the Orontes valley, Syria, Durham theses, Durham University. Available at Durham ETheses Online: http://etheses.dur.ac.uk/281/

Goossens, R., De Wulf, A., Bourgeois, J., Gheyle, W., and Willems, T., 2006. Satellite imagery and archaeology: the example of CORONA in the Altai Mountains. Journal of Archaeological Science, 336, pp. 745-755. https://doi.org/10.1016/j.jas.2005.10.010

Gurt Esparraguera, J. M., Ariño Gil, E., Martínez Ferreras, V., and Pidaev, S. R., 2015. The Buddhist occupation of Tchingiz Tepe Termez, Uzbekistan in the Kushan period through the ceramic contexts. Archaeological Research in Asia, 3, pp. 1933. https://doi.org/10.1016/j.ara.2015.04.003

Hamandawana, H., Eckardt, F., and Ringrose, S., 2007. Proposed methodology for georeferencing and mosaicking Corona photographs. International Journal of Remote Sensing, 281, pp. 5-22. https://doi.org/10.1080/01431160500104400

Karimov, I.A., 2001. Termez - an Ancient and Modern City at an Important Crossroads. Tashkent, Publishing-poligraphic share company 'Sharq'.

Kokalj, Žiga and Hesse, Ralf, 2017. Airborne Laser Scanning Raster Data Visualization. A Guide to Good Practice. Ljubljana: Založba ZRC.

Leriche, P., 2001. Termez antique et médiévale. In P. Leriche, S.R. Pidaev, M. Gelin, K. Abdullaev and F. Fourniau ed., La Bactriane au carrefour des routes et des civilisations de l'Asie centrale, pp. 75-99. Maisonneuve and Larose, Paris.

Leriche and Pidaev, S.R., 2007. Termez in Antiquity. In J. Cribb and G. Herrmann ed., After Alexander. Central Asia before Islam, pp. 179-211. Proceedings of the British Academy 133. University Press, Oxford.

Leriche, P. and Pidaev, S.R., 2008. Termez sur Oxus: Citécapitale d'Asie Centrale. Maisonneuve and Larose, Paris.

Leriche P., Pidaev S. R., Annaev T., D'Alascio H., Gavison S., Genequand D., Houal J.-B., Moustafakoulov S., Naoumova E., Prisco A., 2002. Mission archéologique franco-ouzbèque de Bactriane septentrionale. Rapport 10, 2002, 78.

Martínez Ferreras, V., Ariño Gil, E., Gurt Esparraguera, J. M., and Pidaev, S., 2014. The Enclosure of Tchingiz-Tepe Ancient Termez, Uzbekistan during the Kushan and Kushan-Sassanian Periods. Iranica Antiqua, 49, pp. 413-469. https://doi.org/10.2143/IA.49.0.3009247

O’Grady; Caitlin R., Luke, Christina, Mokrišová, Jana, and Roosevelt, Christopher H., 2018. Interdisciplinary approaches to understanding and preserving mudbrick architecture in regional and diachronic contexts. Cogent Arts and Humanities, 5, pp. 125. https://doi.org/10.1080/23311983.2018.1553326

Pidaev, S.R., 1991. Kyeramika gryeko-baktriyskogo vryemyeni s gorodishcha starogo Termeza, Sovyetskaya Arkhyeologiya, 1. Academy of Sciences of USSR, Moscow, pp. 210-224.
Pidaev, S.R., 2001a. Contribution à l'histoire ancienne de Termez. In P. Leriche, S.R. Pidaev, M. Gelin, K. Abdullaev, F. Fourniau ed., La Bactriane au carrefour des routes et des civilisations de l'Asie centrale, pp. 47-57. Maisonneuve and Larose, Paris.

Pidaev, S.R, 2001b. Mosquées de quartier dans l'ancciene Tirmidh (Ouzbékistan). Archéologie islamique, pp.61-74.

Schmidt, M., Goossens, R., Menz, G., Altmaier, A., and Devriendt, D., 2001. The use of CORONA satellite images for generating a high-resolution digital elevation model. In IGARSS 2001. Scanning the Present and Resolving the Future. Proceedings. IEEE 2001 International Geoscience and Remote Sensing Symposium Cat. No.01CH37217 Vol. 7, pp. 3123-3125. Sydney, NSW, Australia: IEEE. https://doi.org/10.1109/IGARSS.2001.978277

Schütz, M., 2016. Potree: Rendering Large Point Clouds in Web Browsers. Faculty of Informatics at the Vienna University of Technology.

Shin, S.-W., and Schenk, T., 2008. Rigorous Modeling of the First Generation of the Reconnaissance Satellite Imagery. Korean Journal of Remote Sensing, 11.

Tsantini, E., Martínez Ferreras, V., Ariño Gil, E., Gurt i Esparraguera, J. M., and Pidaev, S. 2016. Pottery Production in the Buddhist Communities in Central Asia: The KushanSassanian Pottery Workshop of Kara Tepe Termez, Uzbekistan: Kushan-Sassanian pottery workshop of Kara Tepe Termez, Uzbekistan. Archaeometry, 581, pp. 35-56. https://doi.org/10.1111/arcm.12161

Ur, J. 2003. CORONA satellite photography and ancient road networks: A northern Mesopotamian case study. Antiquity, 77295, pp. 102-115.

Watanabe, N., Nakamura, S., Liu, B., and Wang, N. 2017. Utilization of Structure from Motion for processing CORONA satellite images: Application to mapping and interpretation of archaeological features in Liangzhu Culture, China. Archaeological Research in Asia, 11, pp. 38-50. https://doi.org/10.1016/j.ara.2017.06.001

Wierzbicki, D., Krasuski, K., and Rykach, S. P. W. 2015. Estimation of rotation angles based on GPS data from a UX5 Platform. Measurement Automation Monitoring, 61 11, pp. 516520. 